\title{
Identification of Acanthocephala on Water Monitor Lizard (Varanus salvator) Human Consumed in Sidoarjo
}

\section{${ }^{1)}$ Ahmad Herdianto Wicaksono, ${ }^{2)}$ Emmanuel Djoko Poetranto, ${ }^{3)}$ Tatik Hernawati, ${ }^{2)}$ Boedi Setiawan}

\author{
${ }^{1)}$ Student, Faculty of Veterinary Medicine, Universitas Airlangga \\ ${ }^{2)}$ Department of Veterinary Clinic, Faculty of Veterinary Medicine, Universitas Airlangga \\ 3)Department of Veterinary Reproduction, Faculty of Veterinary Medicine, Universitas Airlangga \\ Corresponding author: e-djoko-p@fkh.unair.ac.id
}

\begin{abstract}
Water monitor lizards are consumed by humans for its meat. The demand this reptile consumption because the taste and belief of the people in healing disease. Based on habitat and food, they have the potential to transmit zoonosis and have a high possibility of being infested by parasites. One of the possible disease that could infect water monitor and transmitted to human is acanthocephaliasis, infection from Acanthocephalan. Which previous research found Acanthocephala on intestine of frog. This research aims to know and identify Acanthochepala worms that infect water monitor lizards. Based on the results, 40 samples were used and there are 2 positive samples with Acanthocephalan in the body cavity.
\end{abstract}

Keywords: Acanthocephala, Varanus salvator, semichen-acetic, Carmine, transmit, zoonosis

\section{Introduction}

Water monitor lizards are reptile countrymen who belong to the large lizard family, the Varanidae family. Water monitor lizards come from South and Southeast Asia, spread from Sri Lanka and India to Indochina, the Malay Peninsula, and various islands in Indonesia, which live in areas close to water. Based on habitat and food, monitor lizards have a high possibility of being infested by parasites. Several factors that can support the life and development of parasites include unhealthy food, polluted environment, and individual life behavior.

Parasitic worms can be found directly in the digestive tract, for example is Acanthocephala. It is a life-long worm that is parasitic invertebrate intestines. Acanthocephalans also known as thorny-headed worms. Acanthocephala is found in snakes, frogs, and lizards in both cystacanth and adult stages. Stadium cystacanths are found in the abdominal cavity and adult stages are found in the digestive trac.

Acanthocephala has been distributed throughout the world in various definitive hosts of mammals, poultry, amphibians, reptiles and fish.Water monitor lizard (Varanus salvator) is one of the reptile animals found in Indonesia. According to the Convention on International
Trade in Endangered Species (CITES) of Wild Fauna and Flora, monitor lizards are included in the list of appendices II, which means they are not endangered, but these animals are feared to be endangered especially if there is illegal hunting and trading without supervision and empowerment.

Nowadays the desire of the people to make reptiles as livestock starts a lot in Indonesia. Lizard is an animal that has commercial potential. Until now, research on monitor lizards, especially parasites in the digestive tract is still very limited. Based on the description above, the researchers wanted to do research on the identification of parasites in the digestive tract of water monitor lizards (Varanus salvator) in Tulangan, Sidoarjo, which allegedly contained Acanthocephala worms in the intestine of the water monitor lizard, where previous research on this matter had never been done in Tulangan.

\section{Materials and Methods}

The samples to be used in this study were water monitor lizards caught by collectors in Tulangan, Sidoarjo, which have been stored and would be distributed for consumption. In this study, 40 samples of water monitor lizards were collected by collectors and the sample has gone through the necropsy process, the worms found 
put into pots containing saline solution as the sample preservative then labeled with the sampling date.

Acanthocephala which has been found fixed between glass objects using threads that are tied not too tight at the left and right ends of the glass object. The worms were soaked in $5 \%$ glycerine alcohol solution for 24 hours then put in $70 \%$ alcohol for five minutes. A glass of wormcontaining object is put into a carmine solution that has been diluted and left to dry for approximately eight hours depending on the thick-thin worm cuticle. The worm was removed from the glass of the object and put in acidic alcohol for two minutes then into alkaline alcohol for 20 minutes. Then alcohol dehydration was carried out starting from $70 \%$ alcohol to $95 \%$ alcohol each for five minutes, then mounting with Hung's I solution for 20 minutes then taken and placed on a new glass object and dripping Hung's II solution sufficiently above the worm then covered with a glass cover. The last stage ofcoloring is dried in an incubator at $37^{\circ} \mathrm{C}$, then stored at room temperature. Coloration uses the SemichenAcetic Carmin method referring to (Kuhlmann, 2006). After then, observe with the Lucida microscope to give the main representative of the worm

The data from the identification of parasites in the intestine of monitor lizards consumed in Tulangan Subdistrict, Sidoarjo Regency are presented descriptively.

\section{Results and Discussion}

Based on this research using 40 samples of commonly human consumed water monitor (Varanus salvator) from a collector in Sidoarjo from September until October 2019. Two from 40 samples identified are positive infected Acanthochephala. The identification of positive samples on water monitor (Varanus salvator) using Semichen-Acetic Carmine method according to Kuhlmann (2006) and continued to check on lucida microscope. From macroscopic overview of Acanthocephala was found in body cavity of Varanus salvator (Fig. 1). The measurement process is done with a ruler to determine the length of Acanthocephala (Fig. 2).

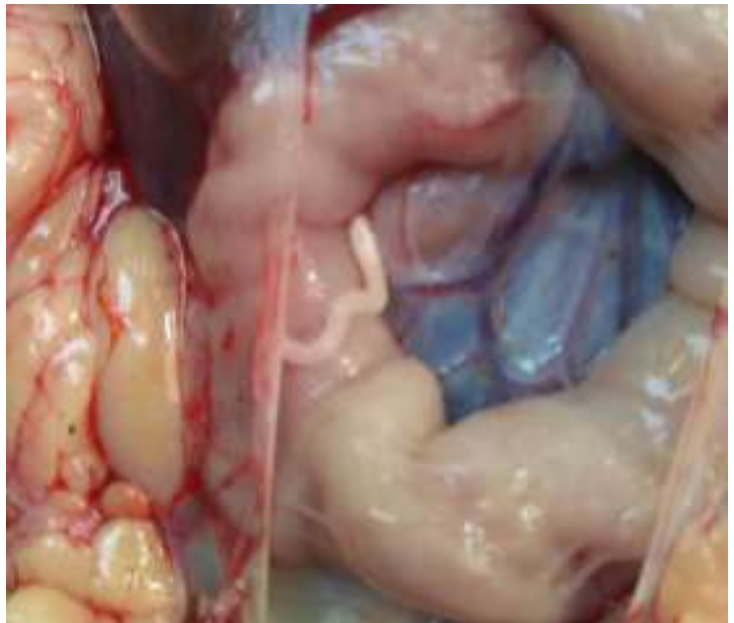

Figure 1. Acanthocephala attach to host's abdomen

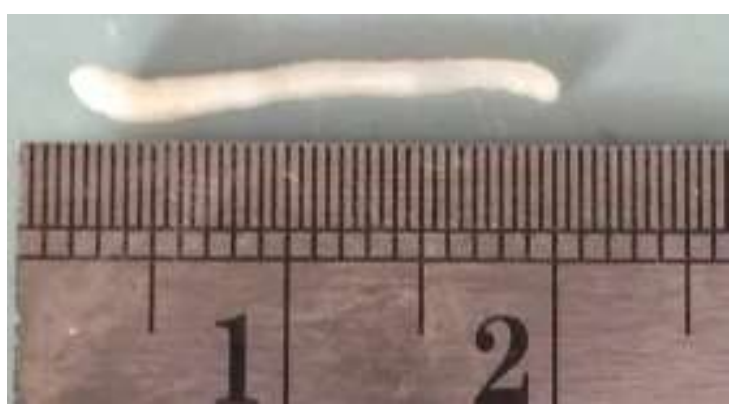

Figure 2. Acanthocephala length measurement

Microscopic overview of acanthocephala under microscope using 4ox magnification Externally can be divided into the retractile proboscis, hook-bearing, smooth neck region and trunk. In microscopic identification can be seen the thornyhead of acantocephala in round shape with spine attach to the neck.

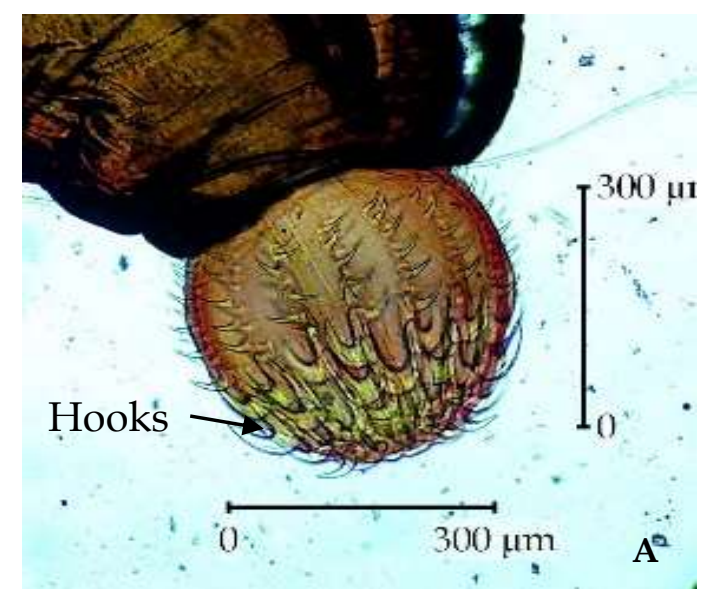




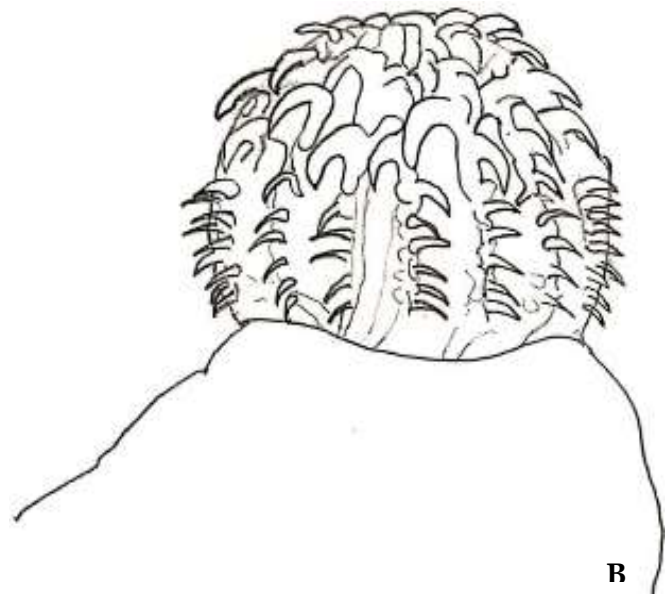

Figure 3. Anterior of Acanthocephala, A = with 10ox magnification using DSLR-microscope with $300 \mu \mathrm{m}$ scale bar, $\mathrm{B}=$ with Lucida microscope

The anterior part of the acanthocephala has a proboscis which is covered with hooks, and is attached to the trunk by a neck. These hooks makes the worm attach securely to the predilection. Also the number and the arrangement of hooks and shape of the proboscis are the primary character used to distinguish the species. The figure showing the proboscis more clearly with various number of hooks. (Fig. 3).

Based on the result of this research form 40 samples that were used from water monitor collectors in Sidoarjo, 2 positive samples have Acanthocephala in body cavity of Varanus salvator.

Acanthocephala was found in the body cavity where thereleased worms are in the cystacanth phase or are immature. Not found in the intestine can be caused by several factors, one of which is the season. This study conducted in the dry season. While acanthocephalan more common during the rainy season. Can be caused too by drinking from water exposed to acanthor. From previous study, proved that there positive acanthocephalan infection on frog and snakes. So environment of this acanthocephala's life cycle have possibility exposed to acanthocephalan. However, this research needs further follow up. Acanthocephalan could cause infection called acanthocephaliasis in humans. Clinical manifestation of acanthocephaliasis range from asymptomatic to severe, including abdominal pain, distention, intestinal perforation, loss of appetite, nausea, vomiting, weight loss, constipation, bloody stools, and eosinophilia according to Mathison et al. (2018). Althought there is still not many acanthocephaliasis cases reported in human, a further research will make it easierto identify and differentiate Acanthocephala infection from other helminth infection.

Acanthocephalan were found in body cavity from the samples that were used and there was no specific symptomps or special characteristic in particular of the water monitor lizard in which it was found. It is important to do sampling or data collection for the water monitor lizard that will be sold locally or internationally to prevent transmission of Acanthocephala or any other helminthiasis and there needs to be a supervision with standardized rule for the industry as guarantee for the costumer or everyone that is involved in the industry.

\section{Conclusion}

There was two positive sample were infected with Acanthocephala of all samples and no adult worms were found that infected Varanus salvator. Predilection from Acanthocephala is in the body cavity.

\section{References}

Amin, O., Richard H., Ali H., 2011. The Morphology of an Unique Population of Corynosoma Strumosum (Acanthocephala, Polymorphidae) from the Caspian Seal, Pusa caspica in the Land-locked Caspian Sea using Sem. Acta Parasilogica 56 (4), 438-445.

Bush, A.O., Fernandez J.C., Esch G.W. and Seed J.R. 2001. Parasitism:The Diversity and Ecology of Animal Parasites. The Press Syndicate of the University of Cambridge. United Kingdom. 197-211.

Case Report and Review of Acanthocephaliasis in Humans. Division of Parasitic Diseases and Malaria. 1357-9.

Goater, T.M., Goater, C.P., and Esch, G.W. 2014. Parasitism:The Divesity and Ecology of Animal Parasites Second Edition. The Press Syndicate of University of Cambridge. United Kingdom. 179-197

Kuhlmann, W.F. 2006. Preservation, Staining, and Mounting Parasite Speciment. 8.

Mathison, B, Bishop H, Sanborn C, Souza S, and Brabury R. 2016. Macracanthorhynchus 
ingens Infection in an 18-Month-Old Child in Florida: A

Richardson, D.J. 2013. Acanthocephala. In:eLS. John Wiley \& Sons, Ltd: Chihester. 1-7.

Roberts, L., Schimdt, G. and Janovy, J. 2009. Geralds D. Schimdt \& Larry S. Roberts'
Foundation of Parasitology. McGraw-Hill Higher Education. Boston.

Smales, Lesley. 2007. Acanthocephala in amphibians (Anura) and reptiles (Squamata) from Brazil and Paraguay with description of a new species. The Journal of parasitology. 93. 392-8 